\title{
CONTROL SOCIAL, ESTOICISMO \\ E IDEOLOGÍA ESCLAVISTA. LA REVUELTA DE EUNO EN LA OBRA DE DIODORO SÍCULO
}

Carlos García Mac GaW

UNLP - UBA

cgmacgaw@hotmail.com

Se analizan fragmentos de Diodoro Sículo donde se manifiestan algunos de los mecanismos de dominación de los amos sobre los esclavos. Observamos la representación que se hace desde el discurso dominante del ejercicio del control social y el ocultamiento de las prácticas violentas propias de la relación esclavista. Se trata de fragmentos en donde aparecen referidas situaciones concretas, ocurridas tanto en el ámbito doméstico como en los espacios productivos. La teoría de la dominación social de O. Patterson y los conceptos del análisis del discurso son fundamentos sobre los que se elabora nuestra perspectiva metodológica.

Estoicismo / esclavitud / control / revueltas / ideología

\section{SOCIAL CONTROL, STOICISM AND SLAVE IDEOLOGY. THE REVOLT OF EUNUS IN THE WORK OF DIODORUS SICULUS}

We discuss fragments of Diodorus Siculus where some mechanisms of domination of masters over slaves occurs. We note the representation of the social control and the will of concealment of the violent practices of slavery made from the dominant discourse. These fragments refer to specific situations that occurred both in domestic and productive spaces. The theory of social domination of $\mathrm{O}$. Patterson and concepts of analysis of discourse are foundations on which our methodological approach is developed.

Stoicism / slavery / control / revolts / ideology 
T a cuestión de las revueltas esclavas, especialmente en relación con sus móviles ha sido un tema recurrentemente tratado por la historiografía. Ciertos autores argumentan que estos levantamientos eran rebeliones fundadas en reclamos reivindicativos por lo que no pueden ser tratadas como revolucionarias ${ }^{1}$. Otros entienden que la búsqueda de un enrolamiento masivo para sostener las guerras esclavas y la violencia abierta consecuente se basan en presupuestos claramente revolucionarios ${ }^{2}$. Apoyamos esta última perspectiva, aunque es necesario matizar el concepto "revolucionario", ya que en general se lo piensa trasladando el imaginario libertario del s. XIX al mundo romano ${ }^{3}$. Es posible superar algunas de estas limitaciones, como el uso del concepto "revolución", si analizamos las huellas de las prácticas discursivas. En particular esto permite revisar el concepto de ideología, como en general se lo alude, es decir como una teoría orgánica de la liberación que debería estar presente para la caracterización de los movimientos esclavos como revolucionarios. Se puede decir que, en general, el conjunto de representaciones que posee una persona conforma su sistema de creencias, y las personas actúan de acuerdo a esos contenidos $^{4}$. Así, la representación de las relaciones sociales de los individuos con sus condiciones materiales de existencia es una ideología, y la ideología dominante de una época es la ideología de la clase dominante, lo que presupone también la existencia de otras ideologías posibles ${ }^{5}$. De esta forma, los conflictos ideológicos se expresan en el plano de las representaciones a través del lenguaje, y, como señala Voloshinov (2009: 47-8), la clase dominante busca imponer su valoración sobre los signos ideológicos por encima del resto de las clases sociales. En nuestro caso entendemos que el texto que analizamos forma parte del discurso dominante y refuerza el control que la clase de los amos ejerce sobre los esclavos ${ }^{6}$. Esta fractura social se sostiene, como argumenta Patterson, esencialmente sobre un

Westermann (1945: 8 ss.), Bradley (1998: 104), Green (1961: 20).

2 URBAINCZYK (2008: 32 ss.).

3 Véase al respecto el artículo de FinLEy (1986: 49-50), quien ha avanzado algunas ideas sobre los usos del concepto "revolución" para el mundo antiguo. Cf. GARCía MAC GAW (2015).

4 RAITER (2012: 17).

5 Althusser(1984: 52), Raiter(2012: 12 ss.). Voloshinov (2009: 43) señala que las formas de comunicación discursiva están plenamente determinadas por las relaciones sociales de producción y por la formación político-social. Sobre esto véase un desarrollo mayor en García Mac GaW (2015: 329-331).

6 Cf. Raiter (2003) sobre el discurso dominante. El hecho que destaquemos que el texto de Diodoro tiene esta orientación va en el sentido de que no existe un determinismo, sino que su interpretación depende de su propio sentido, su contexto histórico, etc. Aunque en general la teoría del discurso dominante supone que todo discurso que no se oponga abiertamente al dominante termina reforzando su perspectiva.

ARgos 39 (2016) ISSN 0325-4194, pp. 33-48 
desbalance total del poder, donde los esclavos resultan el grupo social más débil en el que se pueda pensar en términos sociológicos ${ }^{7}$.

Los fragmentos de la Biblioteca histórica hacen referencia al primer gran levantamiento de esclavos en Sicilia ocurrido entre c. 136 y 132 a.C. ${ }^{8} \mathrm{El}$ texto fue escrito por Diodoro Sículo durante el siglo I a.C. pero nos llega a través de dos resúmenes más tardíos ${ }^{9}$. El primero corresponde a una colección del patriarca de Constantinopla Focio del s. IX, quien nos transmite un epítome de los libros 34/5. El segundo resumen, de los mismos libros, se encuentra en los Excerpta historica Constantiniana de Constantino VII Porfirogéneta del s. $\mathrm{X}^{10}$. Estos fragmentos son la fuente más importante para el conocimiento del levantamiento de Euno ${ }^{11}$. Aparentemente ninguno de ellos reproduce el texto de Diodoro de forma textual y es probable que haya habido algún tipo de intervención sobre los mismos. El primero de ellos es más conciso, mientras que el segundo nos provee más información. Diodoro probablemente haya usado como modelo, entre otros, un texto anterior de Posidonio de Apamea ${ }^{12}$.

Algunos han entendido que el objetivo principal de la obra de Diodoro era básicamente transmitir una enseñanza moral desde una perspectiva estoica en la cual se enrolaba el autor, especialmente dirigida a las formas del ejercicio del poder ${ }^{13}$. En ese sentido, la cuestión de la esclavitud y de las relaciones entre amos y esclavos tiene un lugar privilegiado en su $\mathrm{Bi}$ blioteca histórica. Farrington (1947: 65-69) destaca la posición contraria del estoicismo frente a la esclavitud pensada como un hecho propio de la naturaleza, especialmente a partir de la obra de Zenón de Citioquien, a inicios del s. III a.C., según el autor "declaró una guerra abierta" contra tales ideas en su manifiesto inaugural, la República ${ }^{14}$. Sin embargo, discusiones

7 Patterson (1982: 1-14). El autor señala que "slavery is the permanent, violent domination of natally alienated and generally dishonored persons" (p. 13).

8 No hay datos ciertos sobre la fecha del inicio de la revuelta, que podría haber ocurrido entre 141 y 136a.C. Tomamos la última fecha por convención, vid. al respecto BRADLEY (1998: 140-141).

9 La Biblioteca Histórica era una historia universal, originariamente compuesta por cuarenta libros de los cuales se perdieron más de la mitad, que se extendía hasta el periodo contemporáneo del autor. Cf. BrAdLEY (1998: 133-136).

10 Esta es una antología de diversos temas cuya recopilación fue ordenada por el emperador, en su mayor parte desaparecida. Un análisis comparativo entre los dos fragmentos en Dumont(1987: 201-203).

11 Bradley (1998: 59). Sobre la revuelta en general vid. Green(1961); Yavetz(1991); BradLEy(1998: 46-65); Shaw(2001: 79-106); Urbainczyk(2008).

12 Parte del texto de Posidonio relativo a la revuelta narrada por Diodoro se conserva en Athenaeus de Náucratis (12.542b). Esto ha dado lugar a especulaciones, cf. un estado de la cuestión en Dumont(1987: 203-213).

13 Stylianou(1998); Green(2006: 24).

14 Garnsey(1996: 129). 
similares ya habían aparecido durante el s. V. El sofista Antifonte destaca en un fragmento que los hombres nacen iguales e incluso extiende esa consideración cuando compara a griegos y bárbaros ${ }^{15}$. Ciertos historiadores entienden que posiciones como la del orador ateniense adquieren una coloración distinta cuando son analizadas en el contexto histórico en el que se encuadran y probablemente no constituyeran un programa político sino que más bien podrían entenderse como una reflexión teórica que exploraba los límites de la acción política democrática ateniense en la crisis final del conflicto militar con Esparta ${ }^{16}$. Como es sabido, la obra de Zenón no ha llegado hasta nuestras manos, por lo que la posición de Farrington se sostiene más bien en inferencias que pueden sacarse de textos posteriores o depende de ciertas perspectivas modernas y especialmente de su propio entusiasmo revolucionario. Por el contrario, la propuesta de quienes sostenían la teoría de la esclavitud natural aparece expresada claramente ya en la Política de Aristóteles (1254a-1256a) ${ }^{17}$. No es éste el lugar, ni es nuestra intención, discutir los criterios generales sobre el enfoque del estoicismo hacia la esclavitud, si es que se puede argumentar que existe un enfoque en lugar de, más bien, diferentes posiciones de acuerdo a los autores y las épocas en el marco de tal movimiento filosófico. Sin embargo, creo que resulta más pertinente la opinión de Green (1961: 19), cuando señala que "thereis no evidence whats oever to suggest an organised moral opposition to slavery as such in the ancient world"18. Y si los propios esclavos tenían esa oposición moral, no ya los intelectuales romanos, sus intenciones no han llegado hasta nosotros. Lo poco que podemos conocer sobre las ideas de Posidonio, el principal filósofo estoico de comienzos del s. I a.C. y probable maestro de Diodoro, se orienta hacia un pensamiento conservador que encontraba en la existencia del Imperio Romano la materialización de la idea estoica de la unión de la humanidad en una única comunidad $^{19}$. De hecho, el mismo Diodoro (1.3.6) indica que su historia es sobre los eventos ocurridos en todo el mundo "tomados como si fueran los asuntos de una única polis"20. Cambiano (1987:49) señala que reconocer

15 DK 87 B 44 = fr. 1 B, col. II; BRUNT (1993: 351).

16 Véase ahora el análisis del fragmento referido en GALLEGO(2003: 378-386), con bibliografía. Sobre Antifonte, vid. pp. 336-339. Vid. Cambiano (2003: 30-32), para el caso de Alcidamas.

17 Vid. SChlaifer(1936: 199-202); Brunt (1993: 345); Cambiano (2003).

18 Vid. tambiénGREEN(2006: 24): "Treating slaves well was not a blueprint, then or later, for abolishing slavery, and Diodorus shows himself a firm supporter of the social hierarchy".

19 GREEN(2006: 21-23),quien sigue a KIDD (1999: 129 y 336-337), y afirma en pp. 23-24 que Diodoro retoma efectivamente fragmentos de la historia de Posidonio relativos a las guerras esclavas sicilianas (cf. Athenaeus 12.542b, 6.272e); WiEDEMANN (2005: 192). Sobre la historia de Posidonio, vid. KIDD (1999: 25-27). Sobre el imperialismo romano y la historiografía de la época, vid. CORSARO(1998: 418-422).

20 Rubincam(1987: 314). 
teóricamente que la esclavitud es injusta, como es el caso de muchos de los escritores antiguos, podía coincidir con la aceptación de su inevitabilidad, y supone que quienes se oponían a la esclavitud, o no la consideraban un hecho natural, o tal vez aceptaran una perspectiva pesimista de la vida. De hecho, quienes pensaron una sociedad sin esclavos la imaginaron antes como una utopía en donde las herramientas se movían por sí mismas y no como un programa político ${ }^{21}$. Brunt (1993: 352) dice que nadie en la antigüedad proponía la abolición y que el debate concernía esencialmente a la justicia de la esclavitud ${ }^{22}$. En el mismo sentido Garnsey (1996:150) señala que la contribución del estoicismo a la teoría de la esclavitud radica en haber cambiado el foco del aspecto legal al moral ${ }^{23}$.

Por lo tanto, partiremos de la idea de un enfoque moralista en la historia de Diodoro, que apunta a explicar las causas del levantamiento esclavo de Euno y sus seguidores como una respuesta a la degradación y los vicios de sus amos en el ejercicio del poder ${ }^{24}$. Esta causalidad es tan fuerte que algunos historiadores han planteado una "simpatía" por parte de Diodoro hacia los esclavos ${ }^{25}$.Como trataremos de demostrar a través de las citas del texto, esto no supone una revalorización de la igualdad material y social entre los hombres ni tampoco una oposición abierta a la esclavitud. La misma, aceptada como un hecho contingente y no como la expresión de una ley de la naturaleza, es tomada como un dato social. Pero el interés de Diodoro no está puesto en los esclavos por sí mismos, sino en la forma en que los amos se relacionan con ellos. De tal relación se desprende un comportamiento moral correcto o incorrecto en el ejercicio del poder doméstico. La corrupción moral que se desprende del segundo caso se extiende desde el enfoque individual al social cuando se pasa del ámbito doméstico a la forma en que los romanos ejercen el poder en el imperio. Difícilmente podría esperarse de aquellos que gobiernan que lo hagan de buena manera si privadamente su comportamiento es reprochable.

Aparece en Diodoro una primera referencia a la cuestión de la esclavitud en el libro 5.38.1-3, en el transcurso de la descripción que realiza sobre distintas regiones del Mediterráneo. El autor se detiene, aunque de manera general, en la forma en que son explotados los esclavos en las minas de la región de Hispania. Pero el foco de la atención está puesto en

21 Athenaeus 6.267e-270a; Arist., Pol. 1253b.33-54; Il. 18.376; Cambiano(1987: 32-33).

22 Vid. también BRunt (1993:366-368). Sobre los estoicos en particular vid. Brunt (2013: 94-95).

23 Vid. en general sobre el estoicismo y la esclavitud GARNSEY(1996: 128-152).Sobre la influencia estoica de Posidonio en Diodoro, véase ahora Strasburger (1965: 43-44)

24 Cf. Corsaro (1998: 426-429), quien destaca la centralidad del concepto de tryphé en Diodoro para explicar la degeneración de las costumbres romanas.

25 FARRINGTON (1947: 73); URBAINCZYK (2008: 81-83). 
la comparación entre el dominio llevado adelante por los cartagineses y luego por los romanos en la región.

En los fragmentos de Diodoro preservados por los resúmenes de la Bibliotheca de Focio (34/35.2.1-23) y los Excerpta de Constantino Porfirogéneta (34/35.2.24-48), se nos presenta a personajes históricos cuyas personalidades están bien definidas a través del relato de la revuelta esclava del 135 a.C. y que sirven adecuadamente a los propósitos de su histo$\mathrm{ria}^{26}$. En el inicio del relato transmitido a través de Focio, Diodoro señala que Sicilia gozó de sesenta años de buena fortuna que siguieron a la caída cartaginesa. Habiendo alcanzado entonces la prosperidad y gran riqueza, los sicilianos comenzaron a comprar gran número de esclavos, conducidos en masa hacia los mercados esclavistas, en cuyos cuerpos aplicaban marcas candentes y señales $(34 / 35.2 .1)^{27}$. Estos eran tratados duramente por sus amos, quienes les brindaban los cuidados mínimos de alimentos y vestimenta. En consecuencia, muchos esclavos terminaban abasteciéndose por medio del latrocinio y había matanzas por doquier, puesto que los bandidos eran como bandas desperdigadas de soldados $(34 / 35.2 .2)^{28}$. Los pretores no se atrevían a reprimirlos por el poder que ostentaban sus amos $(34 / 35.2 .3)^{29}$. Los esclavos, alterados por las privaciones, frecuentemente violentos y golpeados más allá de la razón, no pudieron soportar el trato. Se reunieron cuando surgió la ocasión y discutieron la posibilidad de la revuelta, hasta que finalmente pusieron en acción sus planes $(34 / 35.2 .4)^{30}$.

Resulta evidente que el relato apunta a entender la causa de la revuelta a partir del trato que los esclavos recibían. En un artículo aparecido en 1945, W. L. Westermann planteaba que la institución de la esclavitud en

26 URBAINCZYK (2008:83-84).

27 "O

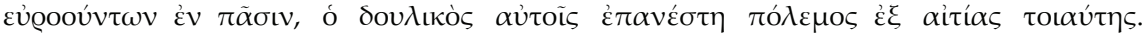

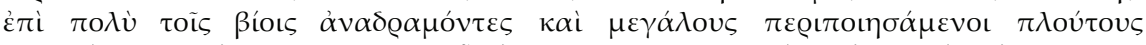

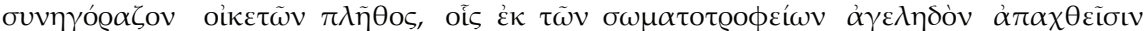

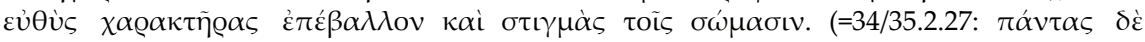

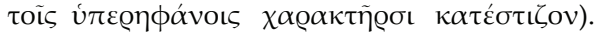

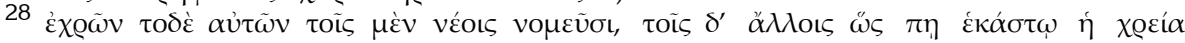

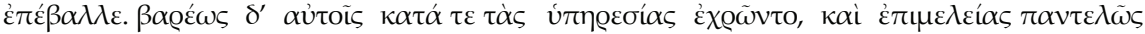

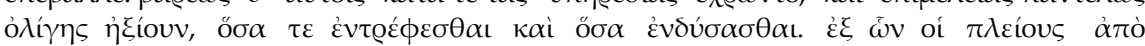

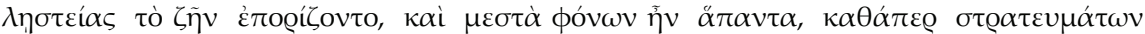

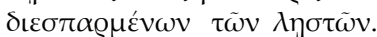

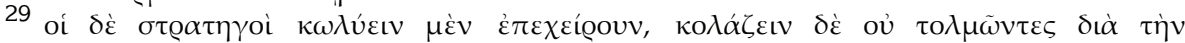

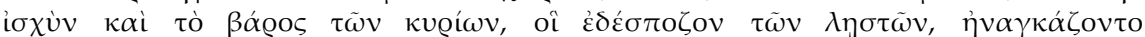

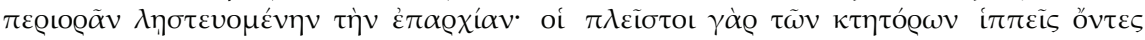

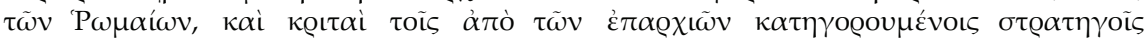

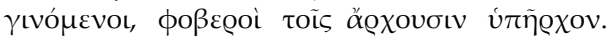

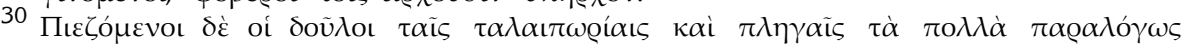

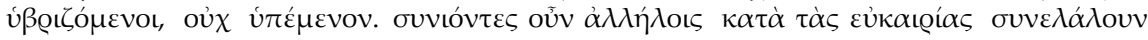

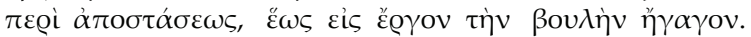

ARGos 39 (2016) ISSN 0325-4194, pp. 33-48 
el mundo greco-romano suponía un tipo de explotación adecuado a ciertas normas no escritas que se consideraban aceptables, aún a pesar de su dureza, y esto suponía un mantenimiento básico representado por alimentos, vestimenta y alojamiento. El autor parte de la idea de una especie de contrato no escrito, aceptado por ambas partes, a partir del cual se organizaba un intercambio de prestaciones. Pone como ejemplo otro tipo de textos, que son registros de las manumisiones por los dioses, o venta al dios, en donde aparece la obligación de cumplir ciertas prestaciones por parte de los manumisos a los proveedores del dinero para la compra de la libertad $^{31}$. Sobre esta base, extiende el caso de las prestaciones debidas en este tipo de acuerdos al caso de la revuelta siciliana. Westermann entiende que, según Diodoro, la ausencia de este mantenimiento mínimo (trophé) habría sido el detonante para la primera guerra esclava en Sicilia. Es cierto que la cuestión aparece específicamente señalada por Diodoro en las versiones de ambos resúmenes: en el más lacónico de Focio (34/35.2.2) ${ }^{32}$, y con mayor abundancia de detalles en el de Constantino. Observemos este último texto más de cerca.

Allí se indica que nunca hubo una revuelta de esclavos como la que estalló en Sicilia, y que para la mayor parte de la gente estos sucesos resultaron extraordinarios e inesperados, pero, para aquellos capaces de examinar a fondo las cosas, estos no habían ocurrido sin razón (34/35.2.25) ${ }^{33}$. Es decir que debemos entender que a través de este relato Diodoro, siendo él capaz de examinar a fondo los hechos, nos explicará las razones del levantamiento. El autor destaca la enorme prosperidad de quienes obtenían productos en esta poderosa isla, y dice que la mayoría de ellos tenía una forma de vida lujuriosa, arrogante e insolente ${ }^{34}$. Por esta causa, en la medida en que el maltrato de los esclavos y el alejamiento de sus amos se incrementaron en igual medida, finalmente, cuando la ocasión se presentó, hubo una violenta explosión de odio (D.S. 34/35.2.26) ${ }^{35}$. Los sicilianos,

31 Westermann(1945: 1-2).

32 “...les daban cuidados escasos, el mínimo de alimento y vestimenta. Como resultado la mayoría de ellos vivía del bandolerismo..." (el texto en griego se encuentra más arriba).

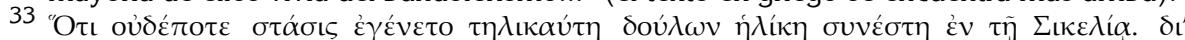

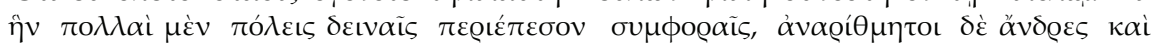

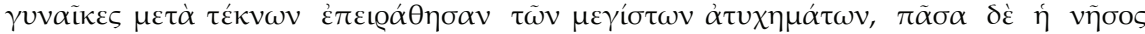

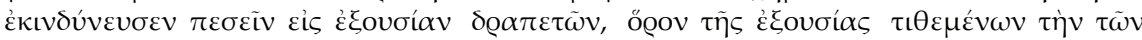

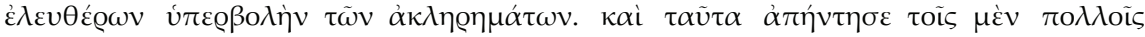

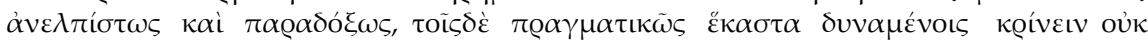

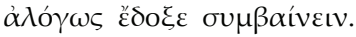

$34=34 / 35.2 .1$ en la versión de Focio.

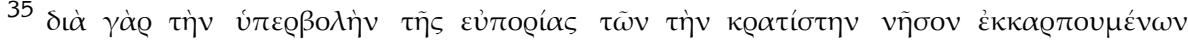

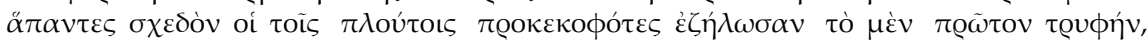

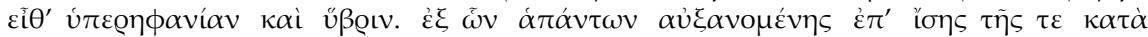

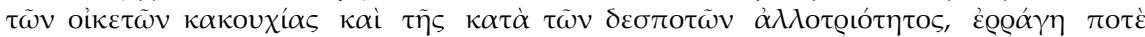

ARgos 39 (2016) ISSN 0325-4194, pp. 33-48 
que habían adquirido tanta riqueza, rivalizaban con los italianos en arrogancia, codicia y villanía. Estos últimos también poseían gran número de esclavos, y a sus pastores frecuentemente en lugar de brindarles alimento les permitían saquear (D.S. 34/35.2.27) ${ }^{36}$. La consecuencia de esta licencia fue el incremento de los asaltos y crímenes a los viajeros en los caminos y el pillaje de los hogares rurales más débiles. La forma de vida salvaje de los pastores al aire abierto y con pertrechos militares, como garrotes, espadas y fuertes bastones aumentó su audacia. De tal forma que todas las regiones estaban llenas de lo que eran prácticamente bandas dispersas de soldados organizadas con el consentimiento de los mismos amos. Diodoro no ahorra en la descripción un rebajamiento a una vida bestial por parte de los esclavos (D.S. 34/35.2.28-30) ${ }^{37}$. Los pretores no se atrevían a contener a los esclavos a causa del poder y la influencia de sus amos (D.S. $34 / 35.2 .31)^{38}$.

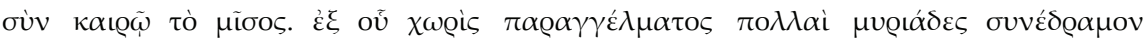

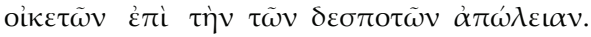

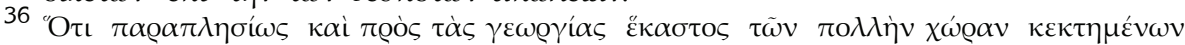

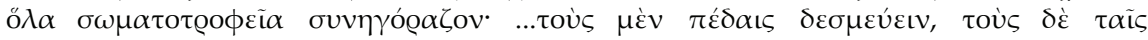

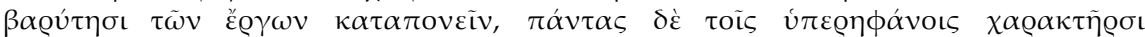

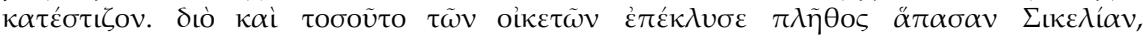

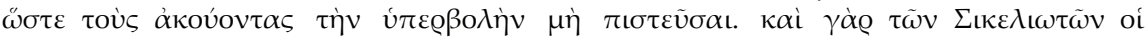

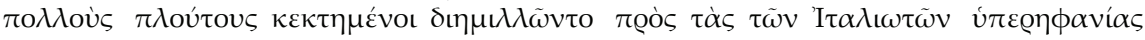

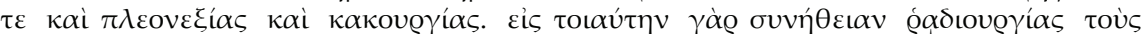

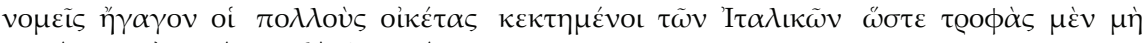

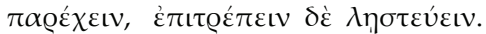

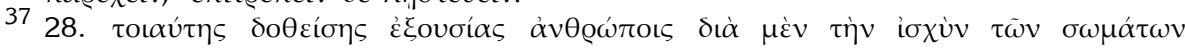

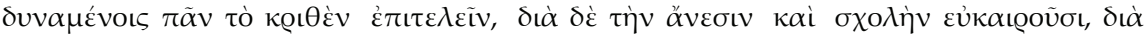

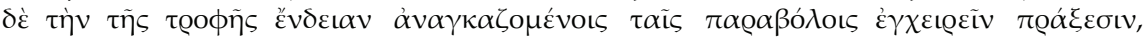

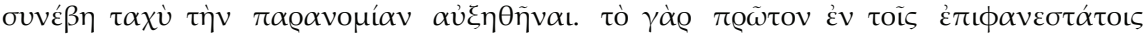

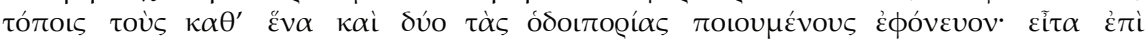

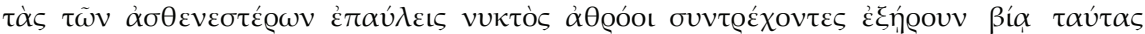

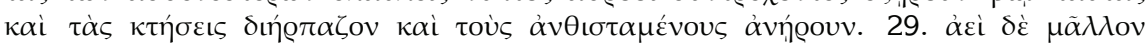

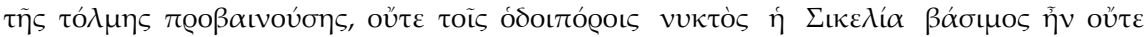

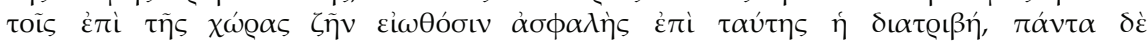

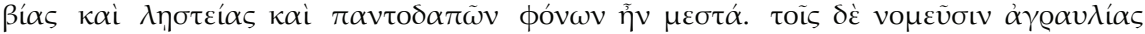

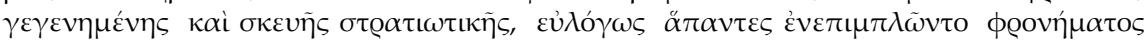

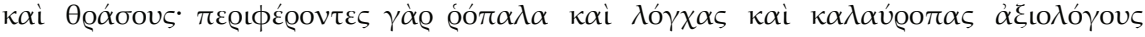

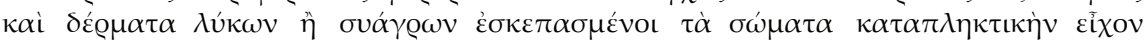

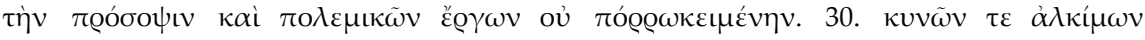

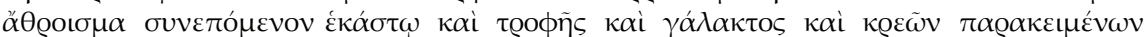

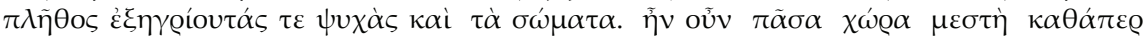

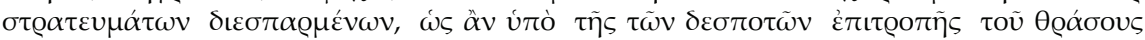

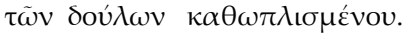

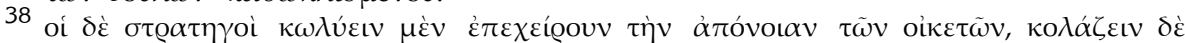

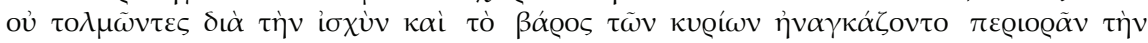

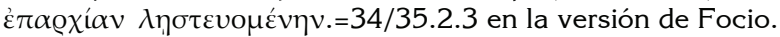

ARGos 39 (2016) ISSN 0325-4194, pp. 33-48 
Vale la pena detenerse en la referencia a la complicidad de los amos respecto de la provisión de las armas para sus esclavos (D.S. 34/35.2.29). Las condiciones en que aparecen retratados los esclavos pastores sicilianos no son excepcionales. Varrón ( $R R 2.10 .1)$, cuando describe las características de los esclavos pastores de Italia dice que los niños alcanzan para arrear al ganado menor si vuelven por la tarde a la villa, pero en el caso de tener que permanecer en el campo convienen los hombres jóvenes "en general armados"39. Esta última condición surge de la necesidad de precaverse contra los salteadores y bandoleros. Muchas veces estos mismos esclavos pastores eran los salteadores de quienes había que precaverse ${ }^{40}$. Las rutas lejanas a las ciudades eran generalmente tierra de nadie y la norma era la inseguridad. La situación en Sicilia se ajusta a estas características pero de manera potenciada.

El capítulo 32 lamentablemente tiene una laguna. Allí Diodoro retoma la descripción de los esclavos comprados en masa por los italianos para el trabajo agrícola, marcados en sus cuerpos (consideración que se repite en varias ocasiones a lo largo de ambos resúmenes), alimentados insuficientemente y explotados opresivamente por medio del trabajo ${ }^{41}$. El texto parece retomar el contenido del capítulo 27 pero está incompleto. El capítulo que sigue elabora una reflexión que parece una conclusión sobre la descripción general realizada hasta allí. Se indica que los hombres prominentes deberían tener consideración con aquellos de baja condición no solo en el ejercicio del poder político, sino que también en la vida privada deberían tratar a sus esclavos cuidadosamente. Al igual que la dureza y la arrogancia conducen a los Estados hacia la guerra civil entre los ciudadanos, en los hogares individuales llevan a las conjuras de los esclavos contra sus amos y a terribles levantamientos contra el Estado. Cuanto más cruel y malvado es el poder, más feroz será el carácter de aquellos sujetos a ese poder, porque aquél a quien la fortuna colocó en una baja condición se rinde frente a sus superiores en cuanto al honor y la estima, pero si es privado de la debida consideración, se levanta contra los déspotas(D.S. $34 / 35.2 .33)^{42}$.

39 Itaque in saltibus licet uidere iuuentutem, et eam fere armatam ...

40 Cf. Corbier(1983), donde la autora analiza un caso en la región de los Abruzzos en época imperial del que pueden sacarse algunas inferencias.

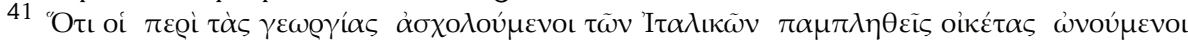

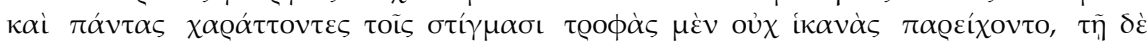

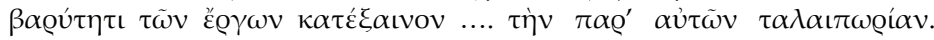

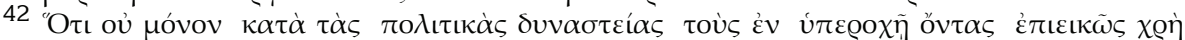

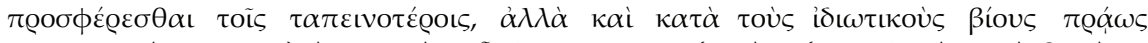

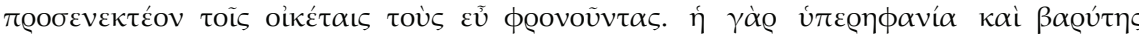

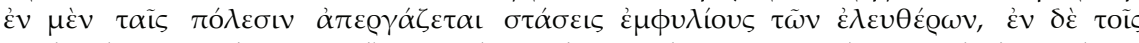

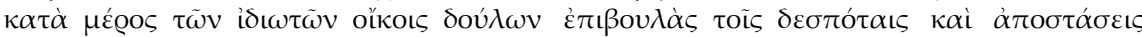

Argos 39 (2016) ISSN 0325-4194, pp. 33-48 
Resulta interesante señalar que el relato de Diodoro trata de justificar los hechos a través del sesgo moral que se le imprime, aún a costa de que el encadenamiento de los mismos pierde en cierto grado consistencia lógica. Como se puede observar, por un lado se plantea la ineficacia de la represión estatal, - los pretores no se atrevían a reprimir a los esclavos levantiscos-, aunque por el otro los amos lo hacían con tal saña que finalmente los llevaron hasta el límite de amotinarse. Por otra parte, si los esclavos estaban organizados en bandas armadas que aterrorizaban a los ciudadanos a través de hechos sangrientos, no sería lógico suponer que los amos podían ejercer una feroz represión en tales circunstancias sino más bien que los esclavos a esa altura ya se encontraban fuera de control. Esta actitud ambivalente del relato a lo sumo explicaría en un caso una profundización de la violencia del levantamiento, en el otro el surgimiento de condiciones de posibilidad para su emergencia dado el progresivo control que las bandas armadas de esclavos habían logrado sobre amplias regiones de Sicilia.

En este punto Diodoro pasa del relato de los hechos más generales al tratamiento del caso específico de un terrateniente, Damófilo, en el seno de cuya familia se desencadenó la rebelión servil (D.S. 34/35.2.34 ss.) ${ }^{43}$. Estos hechos son narrados con mayor detalle, y retoman las condiciones generales ya reflejadas para el conjunto dela elite de Sicilia. Damófilo era un gran propietario nacido en la ciudad de Enna, enormemente rico, de carácter arrogante y dedicado a la cría de ganado. Poseía un gran número de esclavos a quienes trataba de forma severa e inhumana. Diodoro (34/35.2.35) nos presenta una evolución negativa en la personalidad de Damófilo por causa de la ambición, que pasa de la saciedad, al orgullo arrogante y finalmente a la destrucción para sí mismo, produciendo a la vez grandes calamidades para su comunidad ${ }^{44}$. El trato otorgado a sus

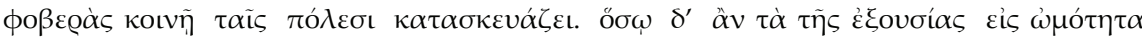

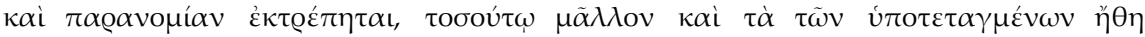

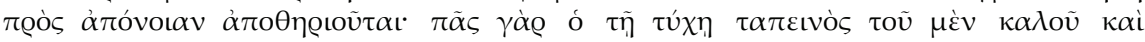

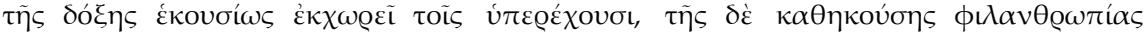

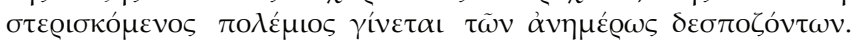

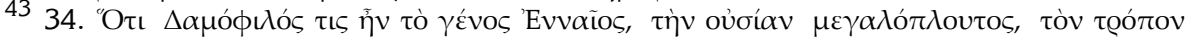

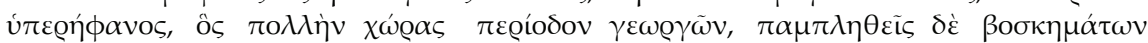

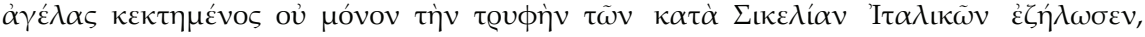

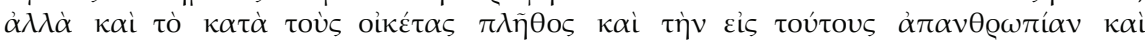

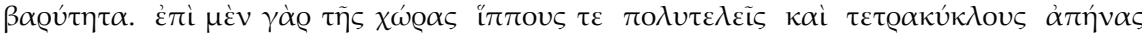

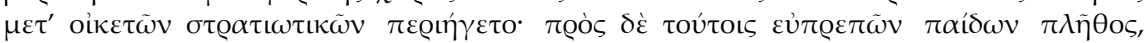

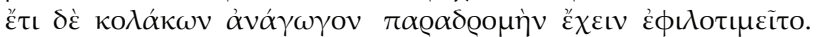

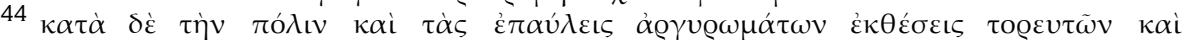

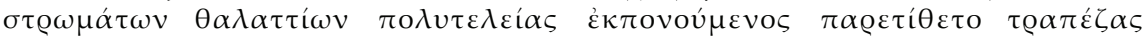

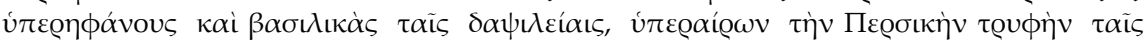

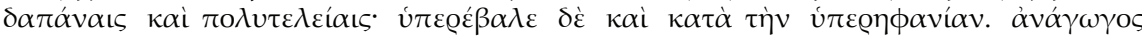

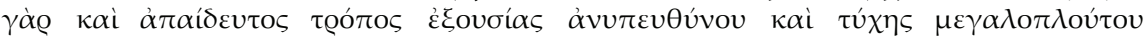

ARGOS 39 (2016) ISSN 0325-4194, pp. 33-48 
esclavos reproduce las condiciones ya apuntadas en relación con las marcas, cadenas, encierros y, para el caso de los pastores, la negación de la provisión de comida y alimentos (D.S. 34/35.2.36) ${ }^{45}$. En 34/35.2.38 se describe una situación en la que un grupo de esclavos desnudos le piden vestimentas a Damófilo y él se niega a escucharlos indicándoles que los viajeros que atraviesan la región ofrecen una inmediata fuente de abastecimiento para sus necesidades, ordenando inmediatamente un castigo ${ }^{46}$. Esta acumulación de excesos llevó al levantamiento de sus esclavos envalentonados por los pronósticos favorables realizados por Euno, un falso profeta que se presentaba como augur de las divinidades y que encabezó la revuelta. Tanto Damófilo como su esposa, quien participaba en los malos tratos hacia los esclavos, fueron ejecutados, junto a gran cantidad de los amos, sus esposas e hijos, de la ciudad de Enna (D.S.34/35.2.40$41)^{47}$. Un elemento destacado por Diodoro es el trato brindado a la hija de

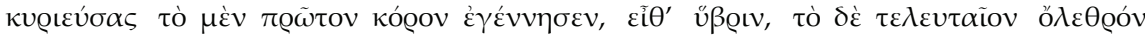

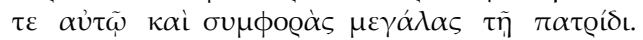

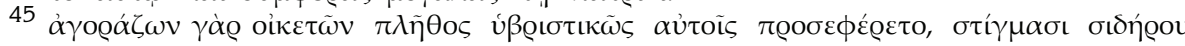

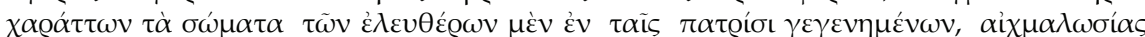

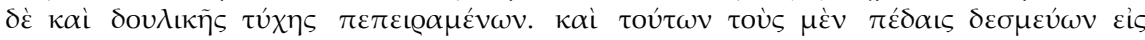

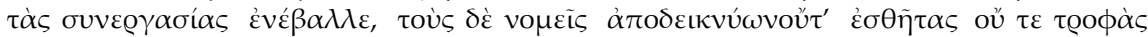

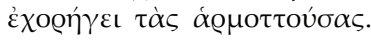

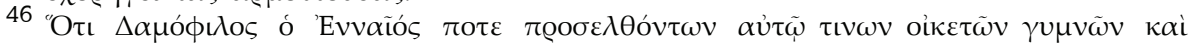

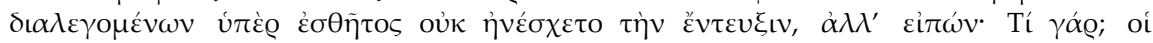

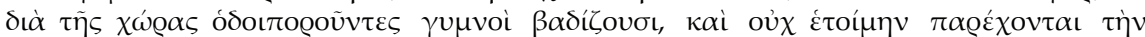

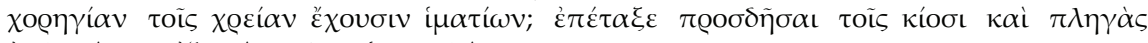

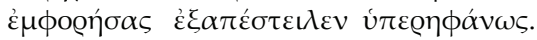

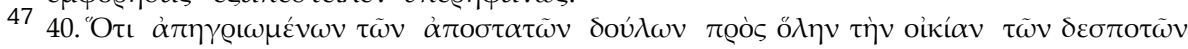

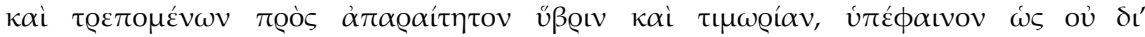

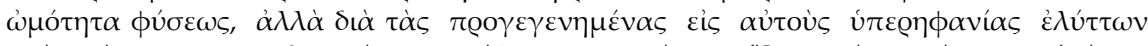

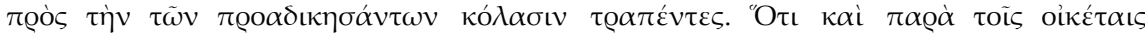

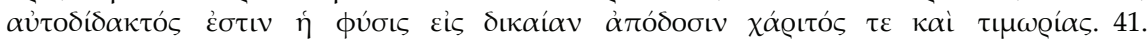

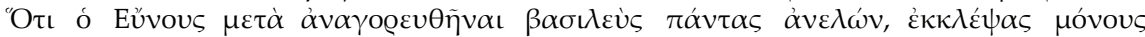

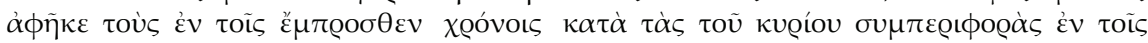

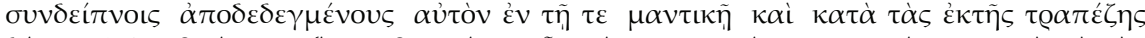

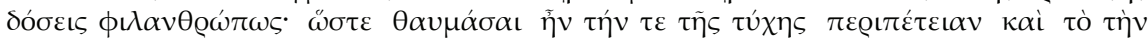

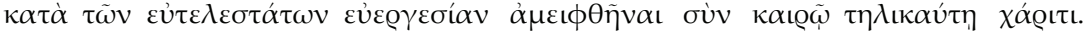

El resumen de Focio (D.S. 34/35.2.11-16) en este caso es más específico en relación

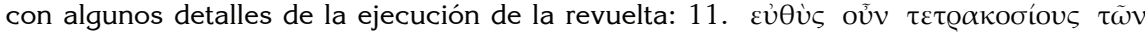

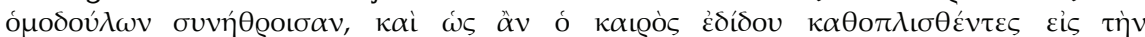

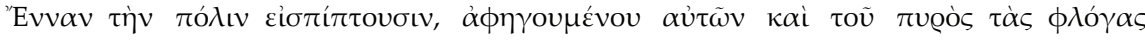

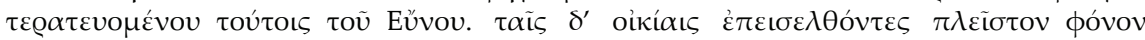

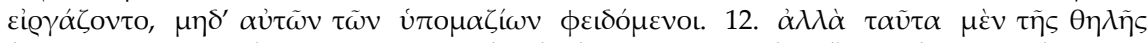

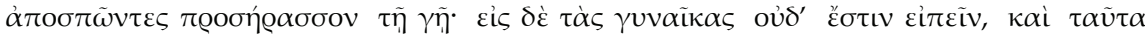

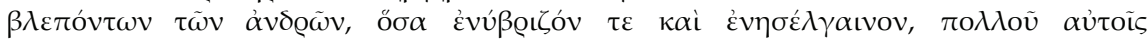

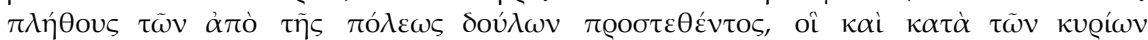

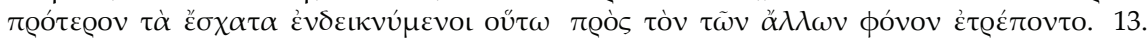

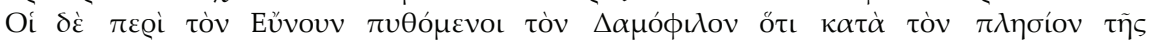

ARgos 39 (2016) ISSN 0325-4194, pp. 33-48 
Damófilo, quien no participaba de los malos tratos realizados por sus padres a los esclavos y solía confortar a quienes habían sido castigados por aquellos. Los revoltosos le perdonaron la vida y la escoltaron a salvo hasta otra ciudad donde vivían algunos de sus parientes $(34 / 35.2 .39)^{48}$. Este hecho es destacado por nuestro autor como evidencia de que los esclavos no se movían por un salvajismo innato, sino que sus acciones eran una respuesta a los ultrajes a que habían sido sometidos, y señala que incluso entre los esclavos la naturaleza humana es perfectamente capaz de decidir sobre cuál debe ser la justa retribución por lo recibido, sea esta la gratitud o la venganza ${ }^{49}$. El epítome de Focio tiene una tendencia que se orienta a la descripción fáctica y militar de los eventos, sin dejar de destacar los aspectos morales que evidentemente tenían un lugar central en el texto de

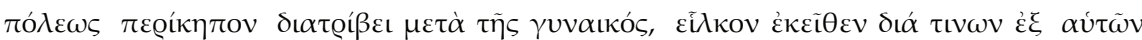

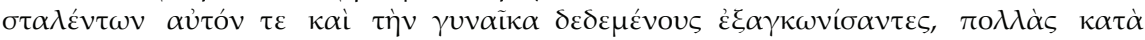

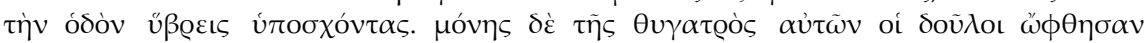

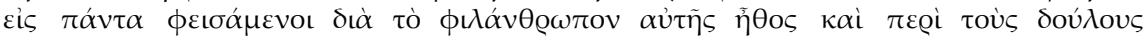

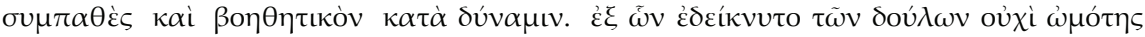

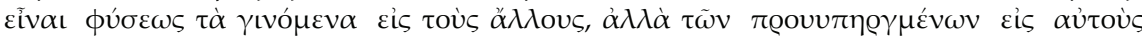

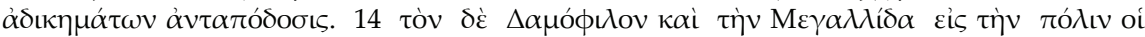

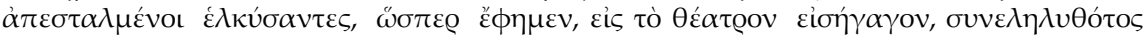

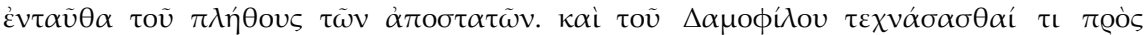

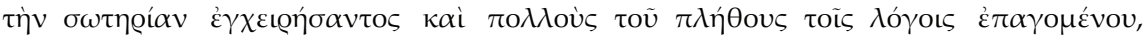

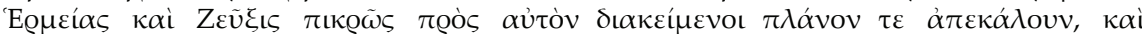

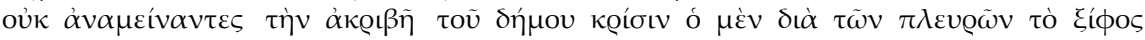

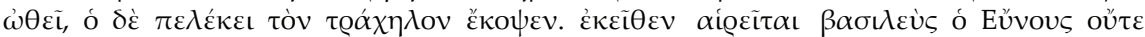

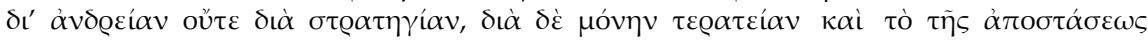

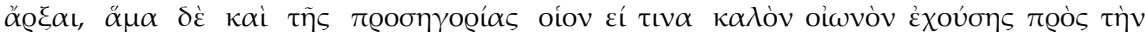

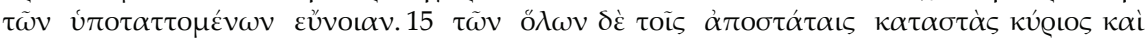

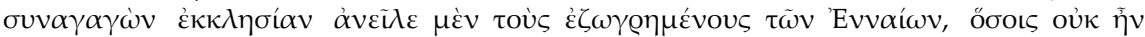

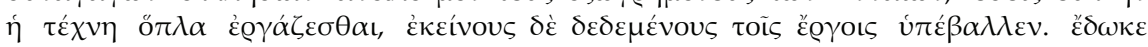

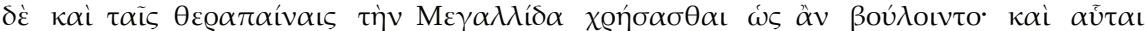

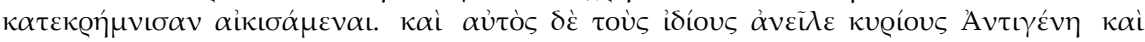

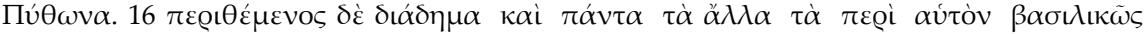

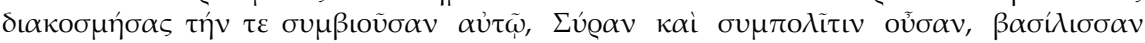

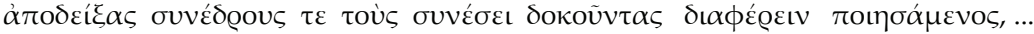

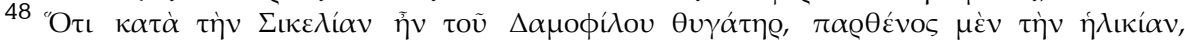

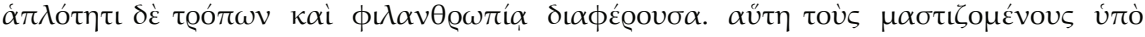

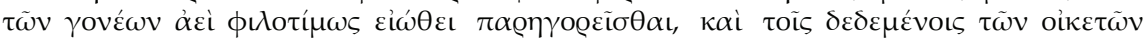

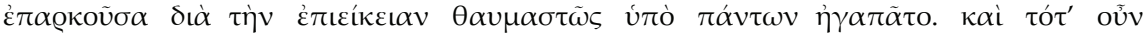

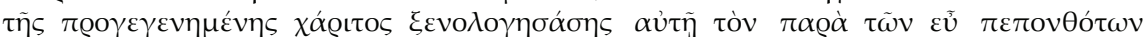

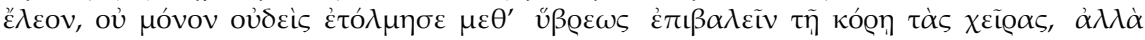

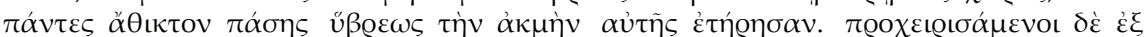

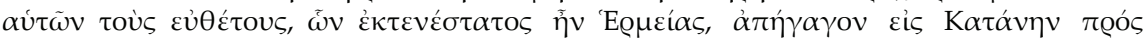

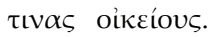

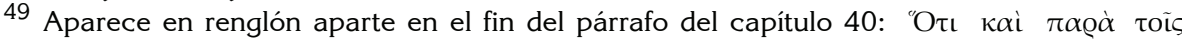

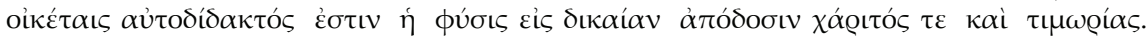

ARGOS 39 (2016) ISSN 0325-4194, pp. 33-48 
Diodoro. Mientras que el texto preservado a través de Constantino insiste de manera más evidente sobre estos últimos elementos.

$\mathrm{El}$ relato coloca en primer plano de manera permanente el comportamiento de los amos que da pie a las acciones violentas de los esclavos. La brutalidad de estas últimas no está cuestionada, sino que encuentra su sentido en las acciones de los libres. Se encuentra aquí un eco de la arcaica discusión de la causa eficiente de la esclavitud, la naturaleza o las acciones de los hombres. De esta forma, nuestro autor entiende que en el caso de la hija de Damófilo los esclavos rebeldes tienen la capacidad de distinguir entre lo justo y lo injusto para retribuir la bondad. Como había indicado en 34/35.2.33, aquellos a quienes la fortuna los había colocado en una condición humilde eran capaces de asumir esa posición si los poderosos actuaban de manera considerada, pero no podía esperarse lo mismo cuando el ejercicio del poder era despótico. Esto de ninguna forma puede entenderse como una crítica a la esclavitud en sí misma, que es entendida como consecuencia de la fortuna que puede advenir a los hombres, sino más bien sobre la forma correcta de actuar de acuerdo a la posición que a cada uno le ha tocado ${ }^{50}$. Diodoro refuerza en su relato la percepción sobre el proceso de degeneración que sufre Damófilo, como individuo, y la clase terrateniente siciliana en su conjunto, tanto los nativos como los itálicos. El enriquecimiento y la lujuria llevan a la ambición y al engreimiento, lo que conduce a la autodestrucción y la catástrofe, ya sea en el caso individual como en el colectivo. Si bien no está dicho concretamente con estas palabras, en Damófilo está ejemplificado el caso de quien se convierte en esclavo de sus pasiones, es decir el caso de la esclavitud de tipo moral ${ }^{51}$, y esa falta de control individual es una parábola que tiene una expresión social ${ }^{52}$.

Diodoro(34/35.2.26) destaca no solo el maltrato de los esclavos, sino también el "alejamiento" de los amos, lo que conduce a la explosión de odio. Esta posición de cercanía debería entenderse en relación con la preocupación por la condición del otro, lo que naturalmente redundará en el reforzamiento del orden social donde cada uno ocupará el lugar que le corresponde. Lejos de ser un discurso contestatario, el texto de Diodoro aspira a lograr que situaciones como la ocurrida en Sicilia no se repitan, y eso depende más bien de cómo deben conducirse quienes se encuentran en las posiciones de poder.

50 Cf. FARRINGTON(1947: 73).

51 Vid. Garnsey(1996: 131-133): "Moral slavery".

52 Cuestión retomada una vez más en 34/35.2.46 donde se relata la dramatización realizada por los esclavos en el sitio de Acragas, y se representa la insolencia y arrogancia de los amos que conduce a su propia destrucción. Vid. ahora GonzalĖs(2013) donde el autor explora elementos semejantes en una obra posterior, el De Beneficiis de Séneca.

ARgos 39 (2016) ISSN 0325-4194, pp. 33-48 
En este sentido, y para finalizar, resulta instructivo observar la manera en que Diodoro(34/35.2.22-23)relata el final de la revuelta conducida por Euno ${ }^{53}$. Las tropas romanas conducidas por el cónsul P. Rupilio sitiaron Enna, luego de recuperar otras ciudades. Euno se fugó "cobardemente" con sus guardaespaldas hacia un terreno escarpado. Viendo que las fuerzas de Rupilio los superaban enormemente, los hombres de Euno se dieron la muerte unos a otros. El "hechicero y rey"Euno, quien "como un cobarde" se había refugiado en una cueva, fue arrastrado afuera con otros cuatro hombres, su cocinero, su panadero, su masajista y quien oficiaba de bufón en sus banquetes. Una vez que fue detenido y encarcelado su cuerpo se convirtió en una masa de piojos ${ }^{54}$, "como corresponde a un hombre digno de sus imposturas" y murió en prisión en la ciudad de Morgantina. He destacado en comillas las precisiones de Diodoro que claramente señalan una mirada crítica y despectiva por la persona del líder esclavo. La "impostura" de Euno está especialmente en relación con su pretendida capacidad para oficiar como intérprete de la voluntad de los dioses y para realizar milagros. Anteriormente Diodoro(34/35.2.5-7)había indicado que Euno fingía predecir el futuro y recibir órdenes divinas a través de los sueños, habiendo engañado a muchos con estas supercherías ${ }^{55}$. Realizaba un truco por medio del cual echaba fuego por la boca, colocándose en ella una nuez agujereada por los dos lados y rellena con material combustible. Cuando soplaba parecía vomitar chispas y llamas. Por otra parte, Euno había sido insólitamente coronado rey en una asamblea de esclavos y se había nombrado a sí mismo Antíoco, siguiendo la tradición siria y toman-

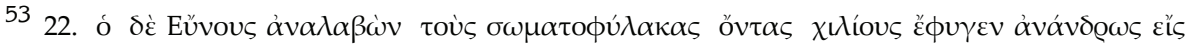

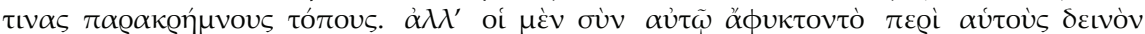

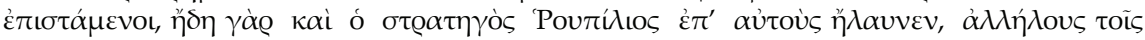

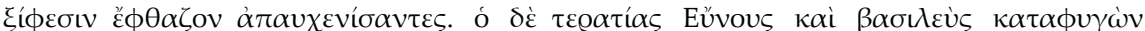

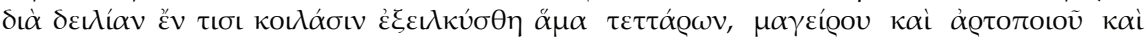

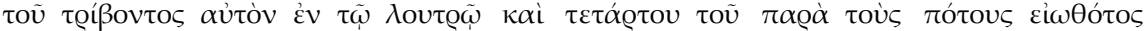

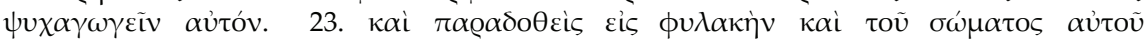

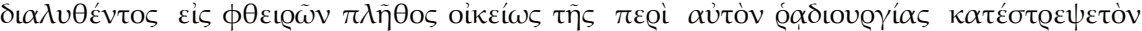

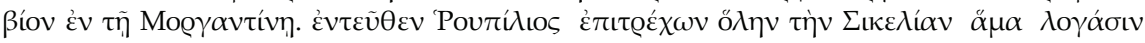

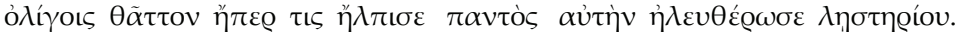

54 BRAdLey (1998: 62), indica que tal vez se tratara de sarna.

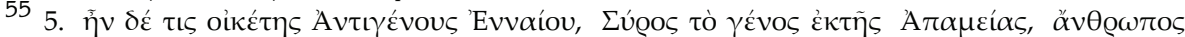

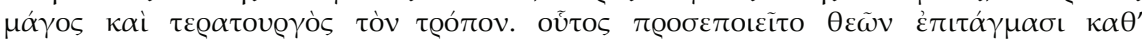

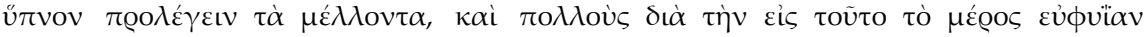

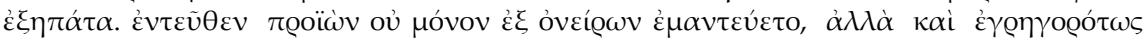

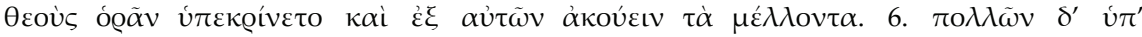

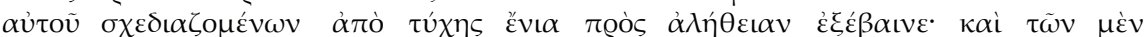

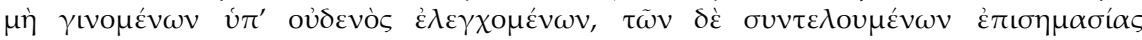

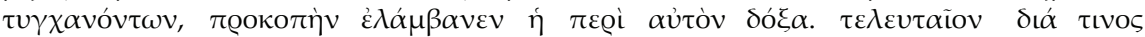

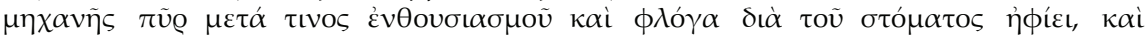

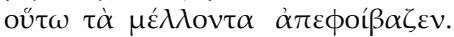

ARGos 39 (2016) ISSN 0325-4194, pp. 33-48 
do el nombre de sus dinastas (D.S.34/35.2.14-16) ${ }^{56}$. De allí que cuando lo señala como "hechicero y rey" Diodoro apela a la ironía en la medida en que entiende que ambos títulos son apócrifos. Los cuatro hombres que se encuentran junto a Euno cuando es apresado son la expresión del refinamiento y la molicie, mientras que la descomposición de su cuerpo en vida resulta un castigo merecido. Como puede verse, el texto de Diodoro está bastante lejos de brindar una mirada cómplice con la revuelta esclava, sin embargo, se puede seguir sin dificultad una línea discursiva cuyo eje central está colocado en la necesidad de un correcto comportamiento para garantizar un eficiente control en el ejercicio del poder.

\section{Bibliografía}

\section{Fuentes}

Athenaeus, Deipnosophistae 6.265d-266d, en SHAw (2001: 64-6).

Athenaeus, The Deipnosophists, transl. by BuRTon Gulick Ch. (1957) in 7 vols., vol. 3, London - Cambridge (Mass.), The Loeb Class. Library.

Diodorus Siculus, Library of History,in12 vols.(1933-1967), Cambridge (MA), The Loeb Class.Library.

Diodorus Siculus 34/35.2.1-3.11, en YAVETZ (1991, 15-24).

Diodorus Siculus 34/35.2.1-3.11, en SHAW (2001: 80-94).

Diodorus Siculus. Bibliothèque historique, Trad. F. Hoefer (1865), Paris.

Obras citadas

BRADLEY, K. (1998) Slavery and Rebellion in the Roman World, BloomingtonIndianapolis.

Brunt, P. A. (1993)Studies in Greek History and Thought, Oxford.

Brunt, P. A. (2013) (ed. by M. Griffin EA. Samuels) Studies in Stoicism, vol. 1, Oxford.

Cambiano, G. (2003) "Aristotle and the Anonymous Opponents of Slavery", en M.I. Finley (ed.), Classical Slavery, London, 28-52 [1a. ed. 1987].

CORBIER, M. (1983) "FiscusandPatrimonium: The Saepinum Inscription and Transhumance in the Abruzzi", JRS 73, 126-131.

CoRSARo, M. (1998) "Ripensando Diodoro. Il problema della storia universale nel mondo antico", MedAnt I.2, 405-436.

\footnotetext{
56 El texto aparece más arriba, en la nota 48. Vid. GARCía MAC GAW(2015: 344-346), para un análisis sobre la situación del coronamiento de Euno desde la perspectiva de la teoría del análisis del discurso.
} 
Dumont, J. C. (1987) Servus. Rome et l'esclavage sous la République, Rome. Gallego, J. (2003) La democracia en tiempos de tragedia. Asamblea ateniense y subjetividad política, Buenos Aires.

García MAC Gaw, C. (2015) "Revueltas esclavas y espacios simbólicos de libertad", en Actas del XXXV Congreso del GIREA: "Los espacios de la esclavitud y de la dependencia en la Antigüedad", Madrid 28 nov. - 30 dic. 2012, Besançon, 327-349.

GaRnSEy, P. (1996) Ideas of Slavery from Aristotle to Augustine, Cambridge.

GonzALĖs, A. (2013) "Le beneficium, l'esclavage et la constructiond'uncontrat moral stoïciendans le De Beneficiis de Senèque", en Campagno, M., J. Gallego y C. García Mac GaW (dir.) Rapports de subordination personelle et pouvoir politique dans la Méditerranée antique et au-delà, Besançon, 283-309.

Green, P. (1961) "The First Sicilian Slave War", Past \& Present 20, 10-29.

Green, P. (2006)DiodorusSiculus, Books 11-12.37.1. Greek History 480-431 B.C.- the Alternative Version, Austin.

Farrington, B. (1947) "DiodorusSiculus, Universal Historian", en Id., Head and Hand in Ancient Greece: Four Studies, London, 55-87.

KIDD, I. D. (1999) Posidonius.Vol. III, The Translation of the Fragments, Cambridge.

Patterson, O. (1982) Slavery and Social Death, Cambridge.

RAITER, A. (2003)Lenguaje y sentido común. Las bases para la formación del discurso dominante, Buenos Aires.

Raiter, A. (2012) "Tus creencias y las de los medios", en A. Raitery J. Zullo (coord.), Esclavos de las palabras, Buenos Aires.

Rubincam, C. (1987) "The Organization and Composition of Diodoros' Bibliotheke", Echos du Monde Classique/Classical Views 31.6, 313-328.

SCHLAIFER R. (1936)"Greek Theories of Slavery from Homer to Aristotle", Harvard Studies in Classical Philology 47, 165-204.

Shaw, B. D. (2001) Spartacus and the Slave Wars. A Brief History with Documents, Boston-N. York.

Strasburger, H. (1965) "Poseidonios on Problems of the Roman Empire", JRS 55, 40-53.

Stylianou, P. (1998)A Historical Commentary on DiodorusSiculus, Oxford.

Urbainczyк, T. (2008) Slave Revolts in Antiquity, Berkeley-Los Angeles.

Voloshinov, V. (2009)El marxismo y la filosofía del lenguaje, Buenos Aires[1a. ed. 1929].

Westermann, W. L. (1945) "Slave Maintenance and Slave Revolts", Classical Philology 40.1, 1-10.

Wiedemann, T. (2005) Greek E Roman Slavery, London-N. York [1a. ed. 1981].

Yavetz, Z. (1991) Slaves and Slavery in Ancient Rome, N. Jersey. 